\title{
APLIKASI PEMBELAJARAN FISIKA DAN MATEMATIKA UNTUK TINGKAT SMP
}

\author{
Malcolm Sebastian Vivaldy, *Oloan Sihombing \\ Program Studi Sistem Informasi, Fakultas Teknologi dan Ilmu Komputer, Universitas Prima Indonesia \\ E-mail: oloansihombing007@gmail.com
}

\begin{abstract}
ABSTRAK- Saat memasuki bangku SMP, siswa akan dihadapkan dengan berbagai pelajaran yang semakin kompleks. Buku per mata pelajaran yang semakin tebal berbanding dengan waktu belajar disekolah yang tidak sebanding, membuat kursus menjadi salah satu opsi jalan keluar bagi siswa agar dapat mendalami pelajaran lebih jauh hingga akhirnya mereka siap untuk menghadapi ujian yang akan datang nantinya. Namun penulis ingin membuat sebuah opsi yang lebih efisien dalam menghemat tenaga, waktu dan biaya dengan simulasi yang lebih mudah dimengerti. Hingga akhirnya dengan latar belakang itu penulis ingin membuat aplikasi pembelajaran di smartphone yang dilengkapi dengan pembahasan dan simulasi soal supaya siswa lebih mudah mengerti pada materi yang sedang dipelajari. Untuk saat ini penulis hanya akan fokus pada 2 mata pelajaran saja yaitu fisika dan matematika. Aplikasi berbasis android dan bangun dengan bantuan aplikasi bahasa pemrograman yaitu Android Studio. Metode yang digunakan untuk mengembangkan aplikasi adalah RAD (Rapid Application Development) karena dapat dilakukan dengan waktu yang relatif cepat. Hasil yang diharapkan dari penelitian ini adalah suatu aplikasi pembelajaran berbasis android untuk siswa tingkat SMP dikhususkan pada mata pelajaran fisika dan matematika, memudahkan siswa untuk belajar dimana dan kapan saja demi menghemat waktu dan tenaga.

Kata kunci: Pembelajaran, Android, Fisika, Matematika, SMP.
\end{abstract}

\section{PENDAHULUAN}

Matematika adalah ilmu pasti dari ilmu lain yang lain. Matematika tidak bisa lepas dari kehidupan manusia. Matematika merupakan suatu perhitungan angka-angka dan ilmu merupakan ilmu dasar pengolahan otak, sehingga di pendidikan sekolah sudah diajarkan dari taman kanak-kanak.

Fisika adalah suatu ilmu disiplin akademik yang paling tua karena ilmu astronomi juga terkandung didalamnya. Lebih dari dua milenia, fisika sudah menjadi bagian dari ilmu alam semesta bersama dengan matematika,biologi dan juga kimia.

Pemanfaatan media pembelajaran dari smartphone diharapkan akan memotifasi siswa SMP untuk mau belajar lebih mandiri, kreatif, efektif dan efisien. Diharapkan juga dengan media smartphone dapat mengurangi kejenuhan siswa dalam belajar.

\subsection{Latar Belakang}

Latar belakang peneliti melakukan penelitian ini adalah karena mata Pelajaran SMP yang semakin kompleks membuat siswa semakin kewalahan. Proses dan keadaan lingkungan belajar dan mengajar yang buruk disekolah terkadang dapat membuat keadaan semakin memburuk. Penyampaian informasi yang tidak efektif membuat siswa tidak dapat mengerti materi yang diajar hingga dapat menyebabkan mereka malas belajar dikarenakan keadaan lingkungan yang tidak kondusif. Disisi lain mereka harus tetap dapat menguasai mata pelajaran tersebut untuk diujiankan nanti, maupun agar ilmu dari pelajaran tersebut berguna dan dapat dipakai masa mendatang nanti.

Peneliti ingin membuat aplikasi pembelajaran khusus untuk mata pelajaran fisika dan matematika untuk siswa tingkat SMP di dalam smartphone mereka yang dilengkapi dengan simulasi yang menarik dan pembahasan agar siswa lebih mudah mengerti dan paham dalam menyelesaikan soal.

\subsection{Tujuan}

Tujuan utama dari penelitian ini adalah untuk mengembangkan aplikasi fisika dan matematika didalam smartphone berbasis android dikhusukan untuk siswa SMP yang baru saja mencicipi pelajaran fisika. Pembahasan dan simulasi diharapkan dapat membantu siswa untuk dapat lebih mudah memahami materi yang dipilih.

\section{ISI PENELITIAN}

\subsection{Android}

Android adalah nama sebuah sistem operasi berbasis linux yang ditujukan untuk perangkat bergerak dengan layar sentuh seperti smartphone dan komputer tablet [1].

Awalnya android dibuat oleh perusahaan android Inc. sampai akhirnya diakusisi oleh google pada tahun 2005. Berkat google, kini android semakin populer, terlebih lisensi yang digunakan adalah lisensi open source.

Pengembangan aplikasi android menggunakan bahasa pemrograman java. Konsep pemrograman java berhubungan dengan Object Oriented Programming (OOP).

Pengembangan aplikasi android membutuhkan software development kit (SDK). Fungsi SDK adalah agar programmer dapat mengakses application programming interface (API) pada android. 


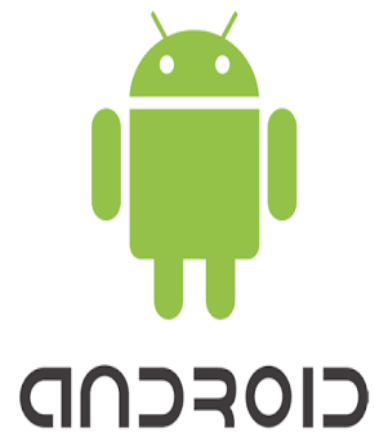

Gambar 1. Logo Android

\subsection{Java}

Java adalah bahasa berorientasi objek yang digunakan dalam mengembangan aplikasi android. Didalam java ada 2 (dua) jenis program yang berbeda. yaitu aplikasi dan applet. Aplikasi adalah program yang disimpan dan dijalankan didalam perangkat lokal sedangkan applet adalah program yang biasanya disimpan diperangkat lain yang jauh dan dikoneksi kan pemakai dengan web browser[15]Hampir semua aplikasi java menggunakan internet terutama aplikasi mobile. Internet dibutuhkan sebagai jaringan global yang menyediakan akses ke informasi dan aplikasi yang menggunakan browser atau web navigasi application [16].

\section{Java Versi Awal}

Versi awal java pada tahun 1996 sudah merupakan veri realease sehingga dinamakan Java 1.0. Java versi ini menyertakan banyak paket standard yang akan terus dikembangkan pada versi selanjutnya.

\begin{tabular}{||l||}
\hline java.lang \\
\hline java.io \\
\hline java.util \\
\hline java.net \\
\hline java.awt \\
\hline java.applet \\
\hline
\end{tabular}

Gambar 2. Logo Android

\section{Kelebihan Java}

Java memiliki beberapa kelebihan yaitu multi platform, OOP, perpustakaan kelas yang lengkap, bergaya $\mathrm{C}++$, pengumpulan sampah yang otomatis.

\section{Kekurangan Java}

Java memiliki beberapa kekurangan yaitu mudah didekompilasi dan penggunaan memori yang banyak

4. Tahap Kompilasi Java

Tahap Kompilasi dari Java yaitu pada Gambar 4.

\begin{tabular}{||l||l||}
\hline \hline Tulis / Ubah & berkas berbentuk .java \\
\hline \hline Kompilasi & berkas berberntuk. class \\
\hline \hline Muat & ke memori \\
\hline \hline Verifikas & memastikan tidak menganggu sistem \\
\hline \hline Jalankan & diterjemahkan \\
\hline
\end{tabular}

Gambar 3. Logo Android

\subsection{Rapid Application Development (RAD)}

Rapid Application Development (RAD) adalah metodologi yang dipercaya paling efektif untuk melakukan pengembangan dengan waktu yang cepat dan mendapatkan hasil kualitas yang baik.

RAD adalah strategi siklus hidup yang ditunjukan untuk menyediakan pengembangan yang jauh lebih cepat dan mendapatkan hasil dengan kualitas yang lebih baik dibandingkan dengan hasil yang dicapai melalui siklus tradisional [2].

RAD merupakan gabungan dari berbagai teknik terstruktur dengan teknik prototyping dan teknik pengembangan joint application untuk mempercepat pengembangan sistem atau aplikasi [3].

Dari penjelasan Pressman, satu perhatian khusus mengenai metodologi RAD dapat diketahui, yakni implementasi metode RAD akan berjalan maksimal jika pengembang aplikasi telah merumuskan kebutuhan kebutuhan dan ruang lingkup pengembangan aplikasi dengan baik [4].

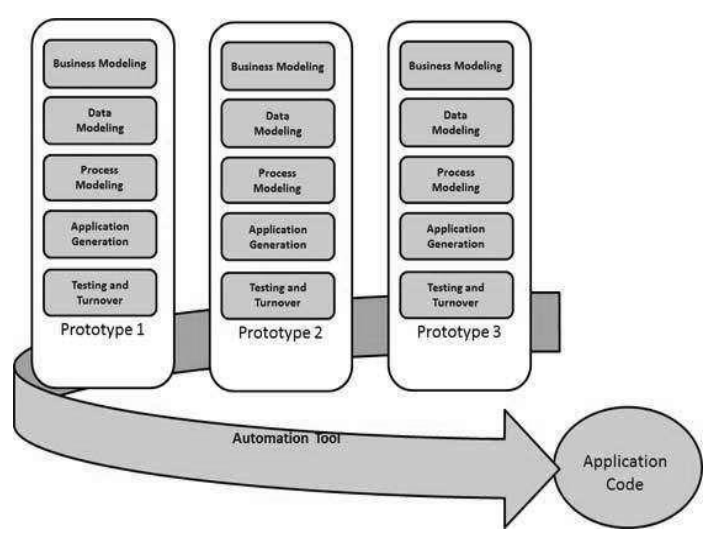

Gambar 4. Fase RAD 
Rapid Application Development (RAD)

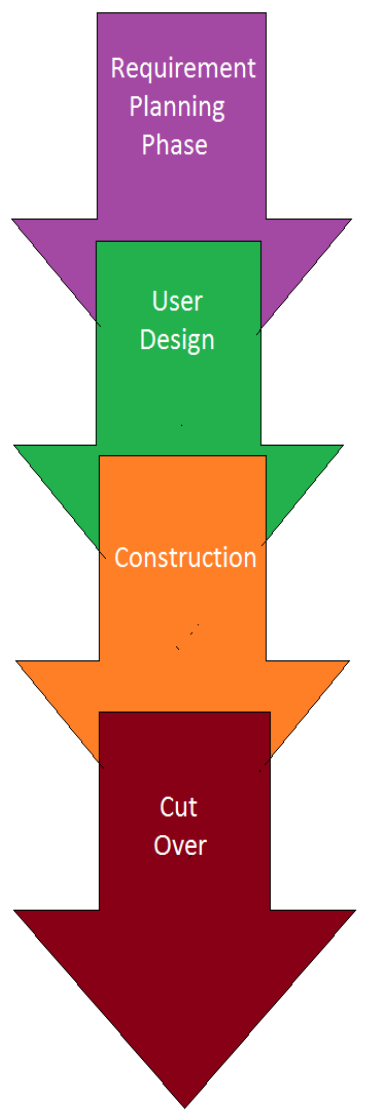

Gambar 5. Proses RAD

1. Fase Pengembangan RAD

Ada 3 fase dalam RAD yang melibatkan penganalisis dan pengguna dalam tahap penilaian, perancangan, dan penerapan. Ketiga fase tersebut adalah requirements planning (perencanaan syarat-syarat), RAD design workshop (workshop desain RAD), dan implementation (implementasi) [6].

2. Kelebihan dan Kekurangan RAD

Metode pengembangan sistem RAD relatif lebih sesuai dengan rencana pengembangan aplikasi yang tidak memiliki ruang lingkup yang besar dan akan dikembangkan oleh tim yang kecil. Namun, RAD pun memiliki kelebihan dan kekurangan sebagai sebuah metodologi pengembangan aplikasi.

Kelebihan dari RAD adalah penghematan waktu keseluruhan fase projek, mengurangi seluruh kebutuhan yang berkaitan dengan biaya dan sumberdaya, perubahan design sistem berpengaruh cepat dibanding pendekatan tradisional, sudut pandang user disajikan dalam sistem akhir melalui fungsi atau antarmuka, menciptakan rasa kepemilikan yang kuat [5].

Kekurangan dari RAD adalah penganalisis terburu-buru, aplikasi tidak diselesaikan secara detail, menyulitkan programmer dan analyt karena dituntut untuk menguasai kemampuan baru [6].

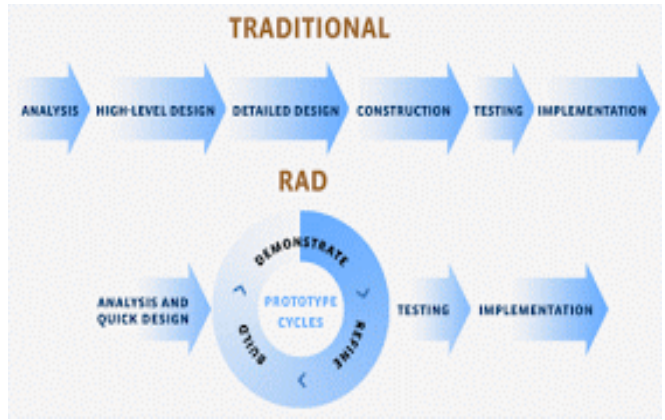

Gambar 6. Perbedaan alur Tradisional dan RAD

\subsection{Android Studio}

Android Studio adalah Integrated Development Enviroment (IDE) pemrograman Android resmi dari Google untuk dikembangkan dari IntelliJ. Sebelum ada Android Studio, programmer Android telah menggunakan Eclipse. Eclipse adalah IDE pemrograman Android sebelum munculnya Android Studio. Bisa dibilang Google telah berpaling dari Eclipse dan menjadikan Android Studio sebagai IDE resminya. Dikarenakan sudah meresmikan Android Studio pada tanggal 16 Mei 2013, Google menghentikan support ADT ke Eclipse tak lama kemudian dan ADT resmi hanya didapatkan oleh Android Studio.

Android Studio dipilih karena memiliki banyak fitur yang memudahkan para pembuat program terutama programmer level dasar yang ingin belajar lebih tentang android. Walaupun pada proses pengunaannya Android Studio cukup banyak menghabiskan RAM pada perangkat PC.

Android memiliki beberapa kelebihan seperti Instant run, Editor kode yang cerdas, emulator yang cepat dan kaya fitur, sistem versi yang fleksibel, optimal untuk semua perangkat Android, dirancang untuk tim, membuat aplikasi yang lengkap dan terkoneksi, integrasi firebase dan Cloud, efektivitas dalam membuat aplikasi.

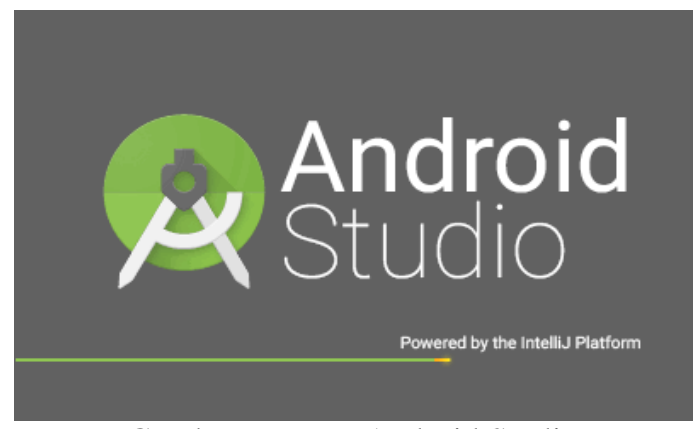

Gambar 7. Logo Android Studio 


\section{HASIL DAN PEMBAHASAN}

Hasil yang diharapkan dari penelitian ini adalah suatu aplikasi pembelajaran berbasis android untuk siswa tingkat SMP dikhususkan pada mata pelajaran fisika dan matematika, memudahkan siswa untuk belajar dimana dan kapan saja, bebas biaya, dan simulasi yang memudahkan siswa untuk mengerti materi yang dipilih. Untuk saat ini hasil masih berupa prototype.

Design dari aplikasi yang masih ditahap prototype ini masih sangat sederhana namun semua fungsi-fungsinya sudah berjalan dengan baik. Design yang minimalis membuat size aplikasi ini juga terbilang kecil tidak memakan RAM yang banyak diharapkan aplikasi ini dapat berjalan disemua jenis tipe android.

Diharapkan penelitian terusannya lebih berfokus pada pengembangan simulasi yang lebih advance. Dimana simulasi dapat mensimulasikan rumus dan input angka dari user.

\section{Tampilan Awal Aplikasi}

Gambar 7 menunjukan tampilan awal aplikasi, dimana pada tampilan ini peneliti memberikan 2 tombol button untuk memilih aplikasi apa yang ingin dibuka adapun itu Fisika atau Matematika.
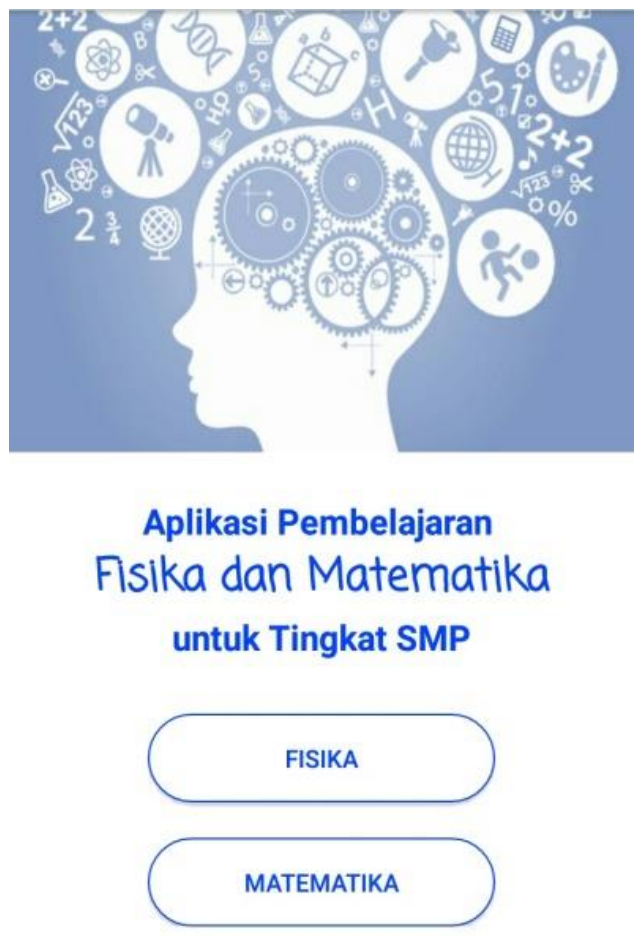

Gambar 8. Tampilan Awal Aplikasi

\section{Tampilan menu list}

Gambar 8 merupakan tampilan list atau daftar dari bab pelajaran yang akan dipilih, design yang sederhana dan sangat mudah digunakan.
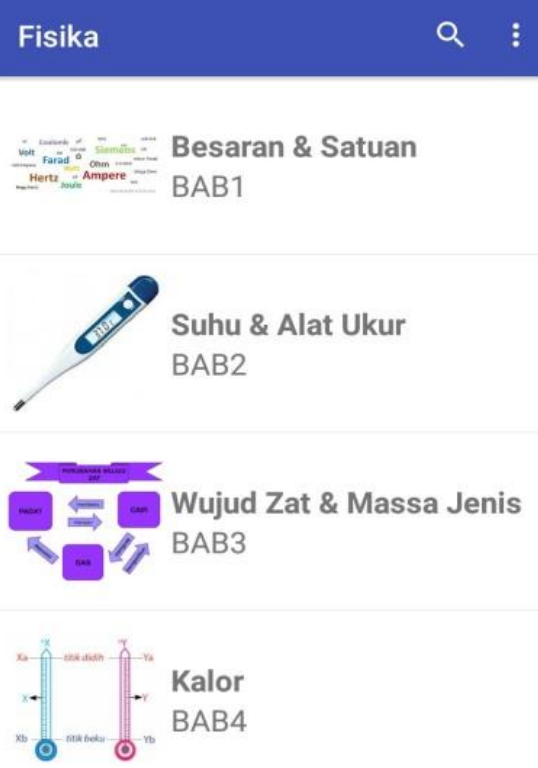

Gambar 9. Tampilan Menu List Matematika

Pada tampilan ini peneliti memberikan fitur search agar pengguna lebih mudah mencari bab mata pelajaran yang ingin dibaca. Metode search pada fitur ini adalah dengan mencari urutan huruf yang dikandung pada menu list.
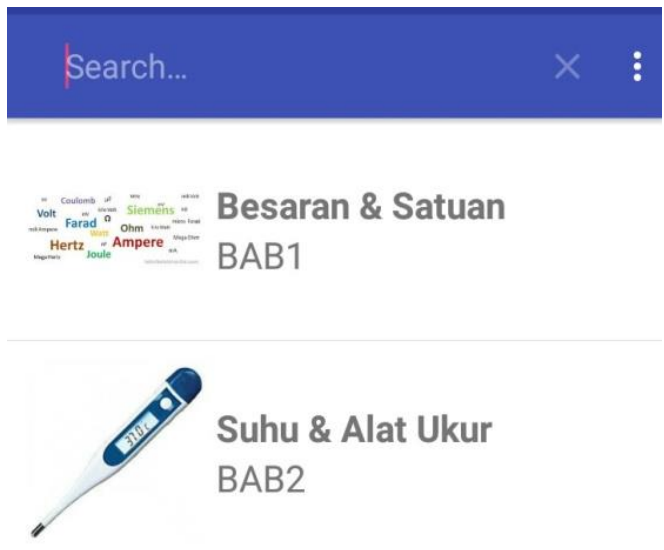

Gambar 10. Fitur Search pada Menu List

3. Tampilan halaman pembelajaran

Gambar 10 merupakan tampilan dari proses pembelajaran yang telah di pilih dari tampilan list. Pada tampilan ini akan dimunculkan isi materi dari bab yang di klik. Untuk saat ini materi dan simulasi masih hanya berupa image. 


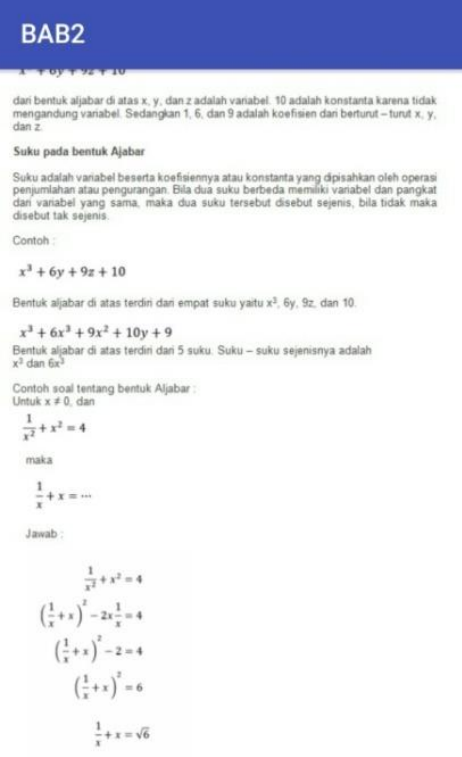

Gambar 11. Proses Pembelajaran

\section{Road map rancangan sistem}

Berikut adalah gambar perancangan Road map dari aplikasi pembelajaran Fisika dan Matematika untuk tingkat SMP.

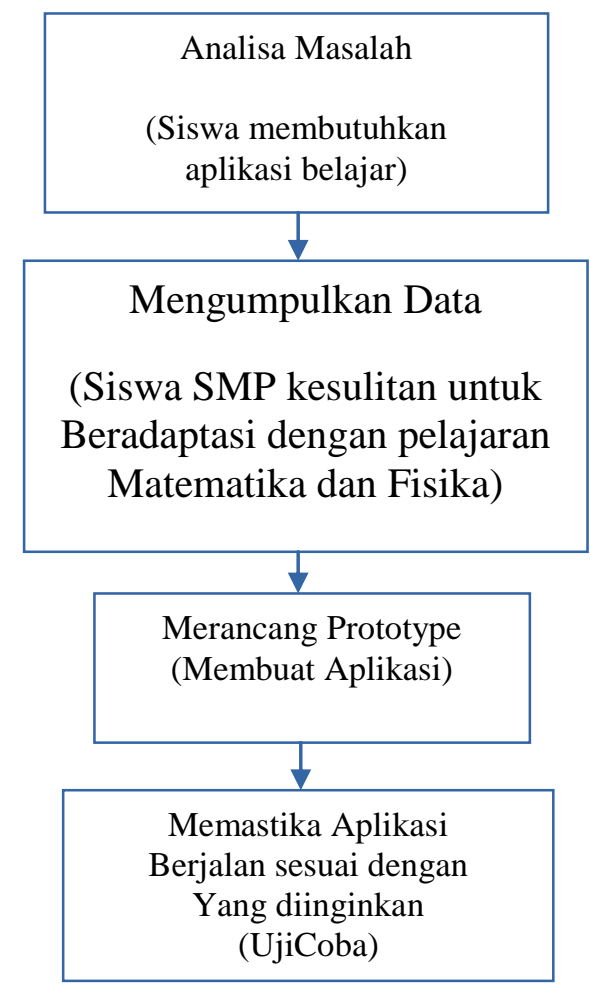

\section{Fisika}

Gambar 12. Proses Pembelajaran

Fisika merupakan sebagai ilmu pengetahuan yang berusaha menguraikan serta menjelaskan hukum alam dan kejadian-kejadian dalam alam dengan gambaran menurut pemikiran manusia [9]. Fisika membangun pengetahuan yang menggambarkan usaha, temuan, wawasan dan kearifan yang bersifat kolektif dari umat manusia
[10]. Fisika sebagai ilmu dasar memiliki karakteristik yang mencakup bangun ilmu yang terdiri atas fakta, konsep, prinsip, hukum, postulat, dan teori serta metodologi keilmuan [11].

6. Matematika

Matematika adalah pola pikir, teorganisir, bukti logis, matematika adalah bahasa yang menggunakan istilah yang didefinisikan dengan cermat, jelas dan akurat representasi dari simbol dan padat, lebih bahasa simbol dari sebuah ide daripada kedengarannya [7]. Unsur-unsur yang tidak didefinisikan, definisi, aksioma dan dalil-dalil di mana argumen setelah terbukti valid pada umumnya, karena matematika ini sering disebut ilmu deduktif. Albert Einstein pernah menyatakan bahwa sejauh hukum matematika mengacu pada realitas mereka tidak yakin dan sejauh mereka yakin, mereka tidak mengacu pada realitas [8].

7. Aplikasi

Aplikasi adalah suatu unit perangkat lunak yang dibuat untuk melayani kebutuhan akan beberapa aktifitas seperti perniagaan, pelayanan masyarakat, periklanan atau semua proses yang dilakukan manusia [15]. Suatu unit perangkat lunak yang dibuat untuk melayani kebutuhan akan beberapa aktifitas seperti sistem perniagaan, pelayanan masyarakat, periklanan atau semua proses yang dilakukan manusia . Program yang memiliki aktifitas pemrosesan perintah yang diperlukan untuk melaksanakan permintaan pengguna dengan tujuan tertentu [12]. Penggunaan dalam suatu perangkat komputer, instruksi atau pernyataan yang disusun hingga sedemikian rupa sehingga komputer dapat memproses masukan menjadi keluaran [13].

8. Internet

Internet adalah jaringan global yang menyediakan akses ke informasi dan aplikasi yang menggunakan browser atau web navigasi application [16]. Kepanjangan dari Internet adalah Interconnection-networking. Jaringan komputer terhubung menggunakan standar sistem global Transmission Control Protocol sebagai protokol pertukaran paket untuk melayani milliaran pengguna internet diseluruh dunia. 


\section{Rancangan Alur Penggunaan Aplikasi}

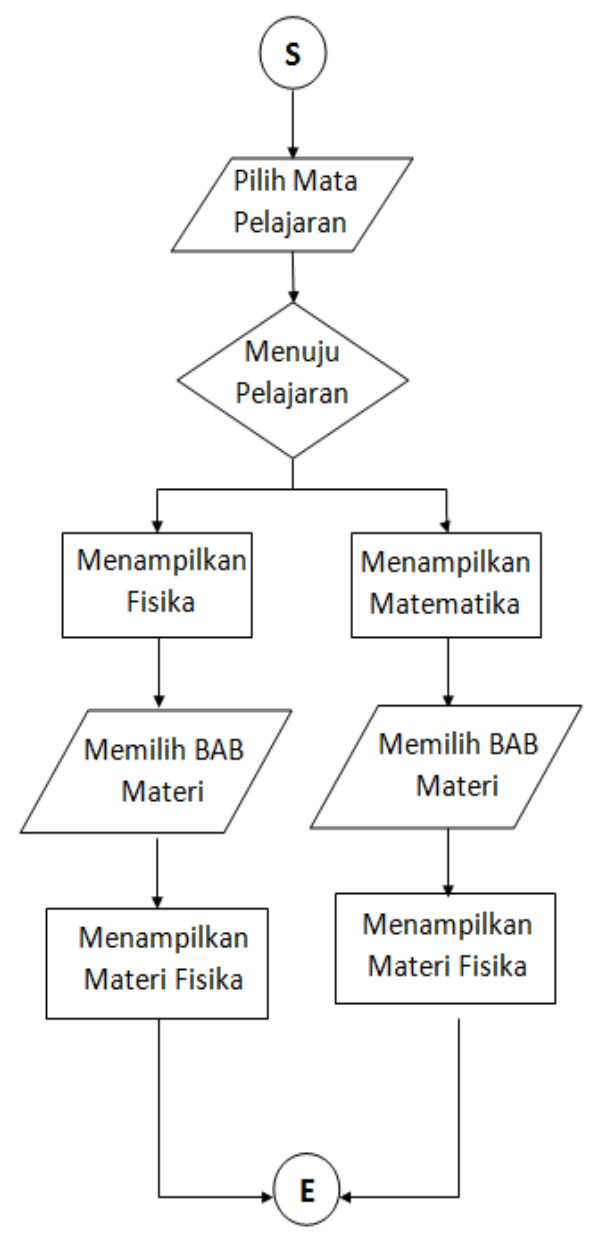

Gambar 13. Gambar Rancangan Alur Aplikasi

\section{PENUTUP}

\section{Kesimpulan}

Berdasarkan penelitian yang telah dilakukan, diperoleh kesimpulan sebagai berikut:

1. Aplikasi pembelajaran Fisika dan Matematika berfungsi dengan baik, fitur tambahan seperti search juga berfungsi dengan baik.

2. Aplikasi pembelajaran memberikan kemudahan karena mudah dibawa kemanapun.

3. UI yang sederhana membuat user langsung dapat menggunakan aplikasi dengan mudah.

Saran dari beberapa responden yang sudah dipersilahkan untuk menguji coba adalah sebagai berikut:

1. Diharapkan kedepannya lebih banyak topik yang dapat dilengkapi diaplikasi ini, seperti pembelajaran biologi dan kimia.

2.Dalam segi isi masih banyak kekurangan dan kurang sesuai dengan standard pelajaran SMP disemua tempat di Indonesia, semoga kedepannya isi lebih ditingkatkan kualitasnya.
Dari peneliti sendiri berharap semoga penelitian ini dapat dikembangkan selanjutnya dikemudian hari nanti memjadi aplikasi yang lebih sempurna dan dapat membantu kebutuhan masyarakat terutama di dunia pendidikan.

\section{DAFTAR PUSTAKA}

[1] Wahana Komputer, Kupas Tuntas Aplikasi Android Bagi Penggila Traveling. Yogyakarta: C.V Andi, 2013.

[2] Mc.Leod.R.Jr, System Development: A Project Management Approach.New York: Leigh Publishing LLC, 2002.

[3] Whiteen. J.L dan Bentley, L.D, System Analysis \& Design Methods: Sisth Edition. New York: Mc.Graw-Hill, 2004.

[4] Pressman, R.S, Rekayasa Perangkat Lunak: Pendekatan Praktisi. Yogyakarta: Penerbit Andi, 2012.

[5] Marakas, G.M, System Analysis Design: an Active Approach. New York: Mc.GrawHill, 2006.

[6] Kendall,J.E \& Kendall, K.E, Analisis dan Perancangan Sistem. Jakarta: Indeks, 2010.

[7] James and James, Van,. Mathematic Dictionary. Nostrand Rienhold, 1976.

[8] Johnson dan Rising, Math on Call : A Mathematics Hanbook, Great Source Education Group, Inc./Houghton Mifflin Co, 1972.

[9] Druxes dan Herbar, Kompedium Didaktik Fisika (terjemahan). Bandung: CV. Remaja Karja, 1986

[10] Wartono, Strategi Belajar Mengajar Fisika. Malang: JICA, 2003.

[11] Mundilarto, Penilaian Hasil Belajar Fisika. Yogyakarta : P2IS UNY, 2010.

[12] Supriyanto, Perancangan Aplikasi. Surabaya: Widyastana, 2005.

[13] Syamsul Rizal, Eko Retnadi, Andri Ikhwana., Aplikasi Pencarian Obyek Wisata Terdekat di Kabupaten Garut Berbasis Android. Jurnal Algoritma Sekolah Tinggi Teknologi Garut, Volume 10 No 1. Sekolah Tinggi Teknologi Garut, 2014.

[14] Janner, Simarmata, Rekayasa Perangkat Lunak.Yogyakarta: Penerbit Andi, 2010.

[15] Simamora, Henry, Management Sumber Daya Manusia. Yogyakarta: STIE YKPN, 2004.

[15] Wikipedia, "Object-oriented programming," Wikipedia, [Online]. Available: https://en.wikipedia.org/wiki/Java.

[16] M.D. Batubara dan E. Indra, "Perencanaan dan Pembuatan Aplikasi Pengerjaan Ujian Nasional Tingkat SMP Berbasis Android," Query: Jurnal Sistem Informasi, vol.02, no.02, p.11,2018. 